\section{The Turnover of Organic Matter in Soil}

\section{By D. S. Jenknsson (Rothamsted Experimental} Station, Harpenden, Herts.)

Under agricultural conditions, organic matter does not accumulate indefinitely in soil. Usually, after a period, annual losses of organic matter balance annual additions, and thereafter the organic matter content of the soil remains constant.

Some of the classical field experiments at Rothamsted, started in the middle of the last century, can be used to estimate the mean residence time of soil organic matter. The organic matter in the top $23 \mathrm{~cm}$. of the unmanured plot in the Broadbalk Continuous Wheat Experiment has a mean residence time of about 50 years, calculated on the assumption that all fractions of the soil organic matter in this field are equally resistant. However, the mean residence time of the organic carbon in soil from the same plot as measured by radiocarbon dating was 1400 years. This soil does not contain charcoal or other carbonized material. The assumption that all fractions of the soil organic matter are equally resistant is thus untenable.

When ryegrass, uniformly labelled with ${ }^{14} \mathrm{C}$, was mixed with soil and allowed to decompose in the field, about two-thirds of the labelled carbon was lost in the first year, but thereafter decomposition was much slower. Even after a year in the field, the labelled carbon was non-uniformly distributed; some fractions had a specific radioactivity 20 times that of others.

Soil organic matter contains materials of vastly different turnover rates: separation into fractions of biologically similar stability is an essential prerequisite to a study of how $\alpha$-amino acids, carbohydrates, amino sugars etc. it contains are protected from attack, in an environment where microbial activity is not limited by $\mathrm{pH}$, aeration, temperature, or availability of nutrients.

\section{Biochemistry of Nitrogen Fixation in Free- Living Organisms}

By M. G. YATES (Agricultural Research Council Unit of Nitrogen Fixation, University of Sussex, Brighton)

Recent progress in this field stems from the discovery (Carnahan, Mortenson, Mower \& Castle, 1960) of a method of obtaining cell-free extracts from the anaerobe Clostridium pasteurianum that fixed nitrogen in the presence of sodium pyruvate. Subsequently, hydrogen and ATP were shown to substitute for pyruvate in this system; it is now known that ATP is necessary for nitrogen fixation with cell-free extracts whatever the organism of source.

Bulen, Burns \& LeComte (1965) reported that cell-free extracts from the aerobe Azotobacter vinelandii reproducibly fixed nitrogen with an ATP-generating system (ADP, creatine phosphate and creatine kinase) and sodium dithionite as the electron source, provided that oxygen was absent. This evidence eliminated oxidative pathways for nitrogen fixation from serious consideration, since extracts from aerobic organisms even require reductive conditions. Hydrogen gas was evolved during nitrogen fixation, and this evolution increased, in amounts equivalent to the ammonia produced, when argon replaced nitrogen in the atmosphere. The manometric determination of this ATP-dependent hydrogen evolution constitutes a new assay for nitrogen fixation that obviates the routine use of isotopic nitrogen in biochemical studies.

Crude nitrogenase preparations from several sources have been resolved by anaerobic column chromatography on DEAE-cellulose into two oxygen-sensitive protein fractions, one of molecular weight approximately 100000 , containing iron and molybdenum, and the other of molecular weight 40000 , containing iron. Both these fractions are necessary for ATP-dependent hydrogen evolution, and fractions from different organisms will crossreact, thus demonstrating the similarity of nitrogenases of different origins.

During 1966-67, several Laboratories reported that nitrogenase preparations reduced other compounds besides nitrogen: acetylene (to ethylene), cyanide ion (to methane and ammonia), methyl isocyanide (to methane and methylamine), azide ion (to nitrogen and ammonia) and nitrous oxide (to nitrogen and water). Like nitrogen, these compounds all possess a triple bond; acetylene reduction is being developed as a sensitive assay for nitrogen fixation in the field.

Chemical reduction of methyl isocyanide usually yields dimethylamine, but when bound to a transition metal as in $\mathrm{PtCl}_{2}\left(\mathrm{C}_{6} \mathrm{H}_{5} \cdot \mathrm{NC}\right)_{2}$, isocyanides gave methane on reduction (Kelly, 1968). If the analogy is valid, then a transition metal is implicated in the active site of nitrogenase; obvious candidates are iron and molybdenum. Side products of the biochemical reduction of methyl isocyanide were ethylene and ethane; it has been suggested that their presence is evidence for an active site for nitrogenase comprising two metal atoms.

Bulen, W. A., Burns, R. C. \& LeComte, J. R. (1965). Proc. nat. Acad. Sci., Wash., 53, 532.

Carnahan, J. E., Mortenson, L. E., Mower, W. F. \& Castle, J. E. (1960). Biochim. biophys. Acta, 44, 520.

Kelly, M. (1968). Biochem. J.107, 1. 